\title{
Hidrodinâmica e composição sedimentar do córrego Jacobina, município de Cáceres, MT, Pantanal
}

Este estudo objetivou avaliar a influência da geologia e do uso e ocupação da terra na composição granulométrica do sedimento da bacia do córrego Jacobina, em Cáceres-MT, Pantanal. Para tanto, a área foi dividida em três compartimentos considerando a geomorfologia local onde, uma coleta de sedimento de fundo e água para análise do sedimento em suspensão foi realizada nos períodos de cheia (fevereiro/2015) e de seca (julho/2015). O sedimento de fundo foi coletado através de uma draga do tipo Petersen e a água através de uma garrafa de Van Dorn. Dados relativos à profundidade e largura do canal, velocidade do fluxo da água e altura do barranco também foram mensurados. Os resultados demonstraram que o córrego Jacobina sedimenta partículas de granulometria mais grossa como areia grossa e média no fundo e o material mais fino tende a manter-se em suspensão nas seções 1 e 2. Na seção 3, o material depositado no fundo é de granulometria mais fina como areia fina e silte. Com relação às variáveis hidrodinâmicas a largura e a profundidade do canal diminuíram da estação chuvosa para a estação seca, diminuindo assim a velocidade do fluxo das águas e a vazão. Os dados demonstraram que o tipo e quantidade de sedimentos encontrados nas seções de coleta podem ser influenciados pelo material geológico e o tipo de uso da terra no entorno da bacia.

\section{Hydrodynamic and sedimentary composition on the Jacobina stream, municipality of Cáceres, MT, Pantanal}

\begin{abstract}
This study aimed to evaluate the influence of the geology and the land use and occupation on the granulometric composition of the sediment of the watershed Jacobina's Stream, in Cáceres, MT, Pantanal. Therefore, the basin was compartmentalized into high, medium and low course considering the geomorphological aspects, where sediment and water samples were collected in each site to analyze the granulometric particulates and suspended sediments on the water in the wet season (February/2015) and the dry season (July/2015). The sediment samples were collected using a Van Petersen dredger and for the water samples a Van Dorn Bottle were used. Data about the depth and width of the channel, water flow and the height of the shore were also performed. The results of the bottom sediment have been shown the Jacobina's stream deposit coarse particle size as such as coarse and medium sand and the fine material tends to remain suspended in both 1 and 2 sites. At the site 3 the deposited material it is fine as such as fine sand and silt. The width and the depth of the channel decreased from the wet to the dry season and the water flow consequently. The data have shown that the type and the amount of the sediment found at the sampled sites, might be influenced by the geologic material and the land use and occupation around at the basin.
\end{abstract}

Keywords: Fluvial Dynamic; Granulometry; Land Use and Occupation; Fluvial Geomorphology.

Topic: Hidrogeografia

Reviewed anonymously in the process of blind peer.
Received: 02/02/2018

Approved: 20/05/2018
Beatriz Ferraz Bühler (iD

Universidade Federal de São Carlos, Brasil http://lattes.cnpq.br/4989365701215549

http://orcid.org/0000-0003-3351-609X

bfbuhler@gmail.com

\section{Celia Alves de Souza iD}

Universidade do Estado do Mato Grosso, Brasil

http://lattes.cnpq.br/4260661798494235

http://orcid.org/0000-0002-9068-9328

celiaalvesgeo@globo.com

\section{Referencing this:}

BÜHLER, B. F.; SOUZA, C. A.. Hidrodinâmica e composição sedimentar do córrego Jacobina, município de Cáceres, MT, Pantanal. Revista Ibero-Americana de Ciências Ambientais, v.9, n.1, p.239-248, 2018. DOI: http://doi.org/10.6008/CBPC2179-6858.2018.001.0017 


\section{INTRODUÇÃO}

O conhecimento sobre a composição sedimentar e a dinâmica de recurso hídrico é um importante instrumento de gestão no que tange ao funcionamento das bacias hidrográficas e suas inter-relações com o meio. A dinâmica fluvial resulta em remoção, transporte e deposição de partículas presentes no sistema de drenagem e embora possa sofrer alterações por pressões antrópicas, os processos sedimentares ocorrem naturalmente em ambientes fluviais (CHRISTOFOLETTI, 1977).

De acordo com Brito et al. (2009) a caracterização dos sedimentos transportados por um curso d'água depende de diversos fatores, como velocidade do fluxo da água, fonte do material e do clima, mas em especial da cobertura vegetal ciliar encontrada às suas margens.

Um rio pode transportar sedimentos tanto em suspensão (carga suspensa), constituída de silte e argila por serem de granulometria menor, quanto ao longo do leito do rio (carga de fundo), constituída de areia, cascalho ou fragmentos de rochas, por serem de granulometria maior (SUGUIO et al., 1990). Desta forma, obter informações sobre o tipo e quantidade de sedimentos transportados em uma bacia é importante para indicar o seu uso direto e indireto, bem como subsidiar medidas de planejamento e gestão do recurso hídrico (SOUZA et al., 2013).

Muitos estudos ressaltando a importância dos aspectos sedimentares em bacias hidrográficas foram realizados no rio Paraguai no estado de Mato Grosso (BUHLER et al., 2012; LEANDRO et al., 2012; SILVA et al., 2013), nacionalmente (BRITO et al., 2009; FARIA, 2014) e a nível internacional (TANANAEV et al., 2013; FRINGS et al., 2014).

Considerando que o córrego Jacobina é um canal fluvial de extrema importância para a comunidade do entorno; considerando ainda que os processos sedimentares na bacia hidrográfica podem estar associados às condições naturais e antrópicas do entorno e também à dinâmica fluvial do rio, o presente estudo teve como objetivo avaliar a influência da litologia e do uso e ocupação da terra na composição sedimentar da bacia hidrográfica do córrego Jacobina, município de Cáceres-MT.

\section{METODOLOGIA}

\section{Área de estudo}

O córrego Jacobina é um importante manancial que abrange a zona rural de Cáceres e abastece muitas propriedades rurais da região para a irrigação agrícola, criação de gado e consequentemente pastagem além de abastecimento doméstico e recreação por parte da população.

Está localizado na região Sudoeste do Estado de Mato Grosso entre as coordenadas geográficas $16^{\circ} 11^{\prime} 51,6^{\prime \prime}$ a $16^{\circ} 17^{\prime} 04,4^{\prime \prime}$ de latitude Sul e $57^{\circ} 31^{\prime} 23.7^{\prime \prime}$ a $57^{\circ} 46^{\prime} 20,1^{\prime}$ de longitude Oeste. $O$ alto curso da bacia hidrográfica do Jacobina está inserido na unidade geomorfológica da Província Serrana e suas nascentes localizam-se entre as Serras da Jacobina e da Campina, sendo que a nascente principal está localizada na Fazenda Córrego Fundo, à margem esquerda da rodovia BR-070 que liga os municípios de Cáceres à Várzea Grande. 
A bacia possui área total de $446,33 \mathrm{~km}^{2}$ e o canal fluvial 52,68 km de extensão, percorrendo várias fazendas de atração turística, de criação de animais e diversos tipos de plantio como as fazendas Córrego Fundo, Jacobina, Figueira Branca, Goiana, Primavera, 4M, Campo Novo, Fordinho e Grendene, desaguando no rio Paraguai pela margem esquerda à altitude de 110 m aproximadamente conforme Figura 1.

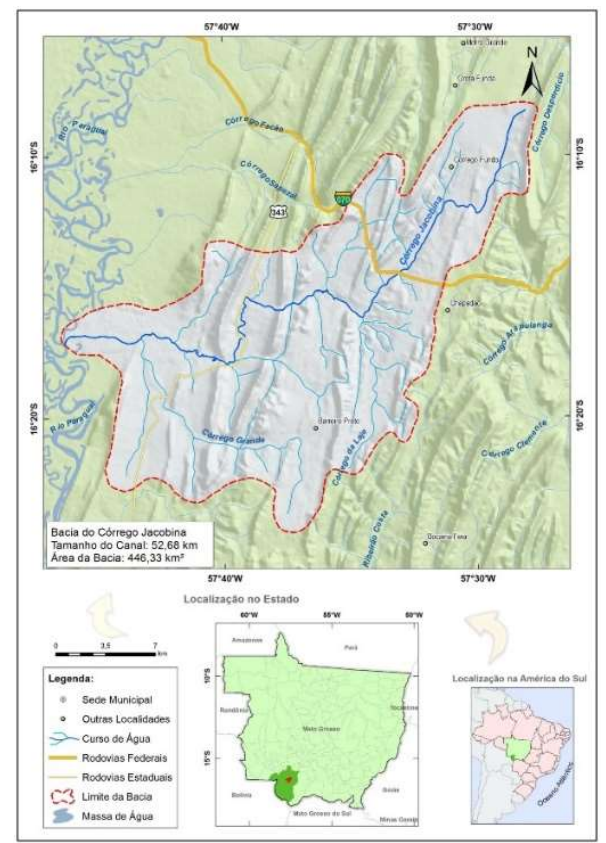

Figura 1. Localização do córrego Jacobina, Cáceres-MT.

\section{METODOLOGIA}

\section{Determinação e caracterização das seções de amostragem}

A área de estudo foi compartimentada em alto, médio e baixo curso, considerando a geomorfologia da bacia conforme Figura 2. Em cada compartimento foi definida uma seção para a coleta de material e levantamento das variáveis hidrodinâmicas.

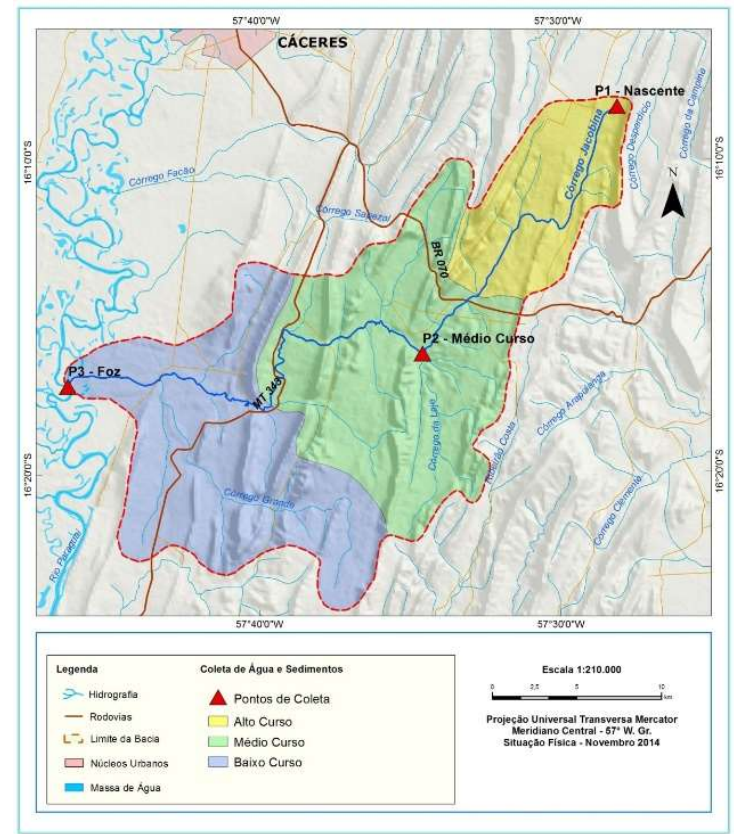

Figura 2. Compartimentos e pontos de coleta de sedimento e água do córrego Jacobina, Cáceres-MT. 
A definição das seções de coleta também considerou aspectos logísticos tais como o acesso por estradas rurais, autorização para entrada nas propriedades e ainda os diferentes tipos de usos da terra do entorno do córrego.

\section{Levantamento das variáveis hidrodinâmicas}

O levantamento das variáveis hidrodinâmicas é uma importante ferramenta utilizada nos estudos sobre a composição sedimentar de uma bacia (FRINGS et al., 2014; LUIZ et al., 2012; MARTINS;STEVOUX, 2005) pois fornece dados que podem indicar o transporte de sedimentos ao longo do curso d'água e ajudam a explicar as diferenças no tipo e quantidade de sedimentos encontrados em diferentes seções amostrais. As variáveis hidrodinâmicas incluem a profundidade e largura do canal, área da seção, altura do barranco, velocidade do fluxo e vazão das águas.

A profundidade do canal foi mensurada através de um ecobatímetro (marca Garmin, modelo 420s). A largura do canal e a altura do barranco foram levantadas com o uso de uma trena. Destaca-se que na altura do barranco, considerou-se a medida do barranco exposto (da superfície da água até o ponto mais alto do barranco em posição vertical). Para medir a velocidade do fluxo da água, foi utilizado o molinete fluviométrico, sendo consideradas três medidas a 20, 50 e $80 \%$ da profundidade apresentada. A área da seção e a vazão da água foram calculadas através da velocidade do fluxo, largura e profundidade do canal. Para o cálculo da área da seção utilizou-se a seguinte equação segundo Cunha (2008):

$A=P \times L$ em que: A= Área da seção $P=$ Profundidade Média

Para o cálculo da vazão utilizou-se a equação segundo Cunha (2008): L= Largura do canal

$$
\begin{array}{r}
\mathrm{Q}=\mathrm{A} \times \mathrm{V} \\
\text { em que: } \\
\mathrm{Q}=\text { Vazão } \\
\mathrm{V}=\text { Velocidade das águas } \\
\mathrm{A}=\text { Área }
\end{array}
$$

\section{Coleta e análise laboratorial do sedimento presente no fundo e em suspensão da bacia}

As amostras foram coletadas nos períodos de cheia (fevereiro/2015) e seca (julho/2015) nas seções previamente definidas. O sedimento de fundo foi coletado por meio de um coletor tipo Petersen e transferido para sacolas plásticas devidamente etiquetadas e identificadas. Para a coleta do material em suspensão, foi utilizada a garrafa de Van Dorn e em seguida o material coletado foi transferido para garrafas plásticas de 1 litro que foram mantidas refrigeradas até o momento das análises em laboratório. Tanto o material de fundo quanto o de suspensão foram destinados ao Laboratório de Pesquisas e Estudos em Geomorfologia Fluvial (LAPEGEOF) da UNEMAT (Universidade do Estado de Mato Grosso) no Campus de Cáceres para análise quantitativa e qualitativa. 
Para determinar o percentual de areia, silte e argila no sedimento de fundo foi utilizado o método da pipetagem (dispersão total) conforme EMBRAPA (1997). Para o fracionamento da areia em grossa, média e fina, foi utilizado o método de peneiramento (SUGUIO, 1973). Para determinação da carga suspensa, utilizouse o método da evaporação conforme Carvalho et al. (2000).

\section{RESULTADOS}

\section{Seção 1}

A primeira seção de coleta localiza-se no alto curso da bacia, na região das nascentes do córrego Jacobina. Embora o entorno do local da coleta esteja dentro dos limites da Fazenda Córrego Fundo, a Fazenda Campina Verde II utiliza-o para a prática de criação de gado bovino mais frequentemente e usa o solo para pastagem dos animais. Nesta seção, a vegetação ciliar encontra-se parcialmente preservada, com árvores de bacuri (Platonia insignis) nativas da região, sendo evidentes alguns focos de erosão principalmente no barranco do córrego, por onde o gado desce para dessedentar à jusante do ponto da coleta.

Nesta seção é possível observar vários afloramentos rochosos de calcário e arenito no sentido transversal ao canal nas estradas rurais, e dentro do canal formando pequenas cachoeiras e corredeiras. Esses afloramentos podem dificultar o fluxo natural das águas e seu escoamento.

\section{Seção 2}

Esta seção está localizada no médio curso da bacia, à jusante da primeira seção e dentro dos limites da Fazenda Primavera que assim como as fazendas da seção 1, praticam a criação de gado bovino e usam o solo do entorno do córrego para pastagem. No entanto, observou-que a vegetação ciliar nesta seção está mais bem preservada quando comparada à seção anterior, mesmo não se encaixando dentro da legislação vigente no que diz respeito às áreas de preservação.

Nesta seção, o volume de água aumenta com o aumento da largura do canal. A presença de travertinos ao longo do trecho entre as seções um e dois, promove aumento da turbulência das águas. Além disso, é possível observar vários afloramentos rochosos no curso d'água que também contribuem para o aumento da turbulência das águas.

À jusante do ponto de coleta existem pequenas quedas d'água que atraem a população local com fins recreativos aos finais de semana, o que se torna uma problemática, pois após o uso, o lixo produzido é deixado no local, degradando o ambiente. A litologia desta seção sofre influência direta da Formação Araras que predomina no compartimento II, com leito do canal rochoso, especialmente por rochas do tipo calcário e arenitos.

\section{Seção 3}

A última seção de coleta está no baixo curso da bacia, onde o córrego desagua pela margem esquerda do rio Paraguai e à jusante da seção dois. Este ponto recebe as águas do córrego que se mantêm lênticas em função da vegetação que se fecha formando uma pequena baía. 
A Fazenda Ressaca é a última propriedade que limita o encontro da água do córrego com a água do rio Paraguai, mas o acesso à propriedade através da margem do rio fica comprometido pela vegetação que dependendo do período, fica mais densa e impede a entrada da embarcação.

A mata ciliar encontra-se bastante preservada e apresenta-se com poucas árvores e muita vegetação arbustiva, com espécies de novateiro (Triplaris americana) nas margens que circundam a baía e macrófitas aquáticas formando vários bancos de aguapés (Eichhornia crassipes e Eichhornia azurea).

\section{Variáveis hidrodinâmicas}

Os dados relativos às variáveis hidrodinâmicas da bacia estão demonstrados na Tabela 1.

Tabela 1. Variáveis hidrodinâmicas considerando os pontos de coleta e períodos amostrais do córrego Jacobina, Cáceres-MT.

\begin{tabular}{|c|c|c|c|c|c|c|}
\hline \multirow[t]{3}{*}{ Variável } & \multicolumn{6}{|c|}{ Período } \\
\hline & \multicolumn{3}{|c|}{ Cheia } & \multicolumn{3}{|c|}{ Seca } \\
\hline & S1 & S2 & S3 & S1 & S2 & S3 \\
\hline \multicolumn{7}{|l|}{ Altura do barranco $(\mathrm{cm})$} \\
\hline Esquerdo & 80 & 190 & - & 72 & 140 & - \\
\hline Direito & 80 & 200 & - & 125 & 102 & - \\
\hline Área da seção $\left(\mathrm{m}^{2}\right)$ & 2,71 & 12,11 & 72,85 & 1,76 & 10,42 & 25,2 \\
\hline Largura do canal (m) & 4,45 & 15,6 & 31 & 3,84 & 14,55 & 28 \\
\hline Profundidade média $(\mathrm{cm})$ & 61 & 77,66 & 235 & 46 & 71,66 & 90 \\
\hline Vazão (m³/s) & 0,06 & 24,35 & 1,82 & 0,044 & 0,86 & 0,63 \\
\hline Velocidade média (m/s) & 0,025 & 2,01 & 0,025 & 0,025 & 0,083 & 0,025 \\
\hline
\end{tabular}

\section{Composição sedimentar}

As fontes de entrada de sedimento para o córrego Jacobina podem ser de várias origens: retirada da mata ciliar; construção de estradas rurais; construção de pontes que ligam estradas rurais; atividades de plantio e criação de animais, entre outras.

\section{Granulometria de sedimento de fundo}

Tabela 2. Granulometria de sedimento de fundo (em \%) considerando os pontos de coleta e os períodos amostrais do córrego Jacobina, Cáceres-MT.

\begin{tabular}{ccccccc}
\hline Período & Seção & Areia grossa & Areia média & Areia fina & Silte & Argila \\
\hline Cheia & $\mathbf{1}$ & 35,95 & 32,1 & 29,7 & 1,65 & 0,6 \\
& $\mathbf{2}$ & 28,62 & 35,26 & 34,21 & 1,32 & 0,59 \\
& $\mathbf{3}$ & 1,49 & 15,83 & 64 & 17,53 & 1,15 \\
Seca & $\mathbf{1}$ & 23,3 & 30,75 & 43,45 & 2,05 & 0,45 \\
& $\mathbf{2}$ & 42,07 & 33,37 & 22,12 & 1,27 & 0,37 \\
& $\mathbf{3}$ & 3,4 & 14,17 & 61,6 & 20 & 0,82 \\
\hline
\end{tabular}

\section{Sedimentos em suspensão}

Os resultados da concentração de sedimentos em suspensão na bacia variaram de $80 \mathrm{mg} / \mathrm{L}$ na seção 3 na estação chuvosa a $560 \mathrm{mg} / \mathrm{L}$ na seção 1 na seca (Tabela 3). Observou-se que em todas as seções a concentração de sedimentos suspensos foi maior na estação seca quando comparado a estação cheia, resultado este que está atrelado à diminuição do volume de águas conforme Figura 3. 
Tabela 3. Concentração de sedimentos suspensão nos pontos de coleta considerando os períodos de cheia e seca no córrego Jacobina, Cáceres-MT.

\begin{tabular}{|c|c|c|}
\hline Seção & & \\
\hline & $\begin{array}{l}\text { Cheia } \\
\text { (mg/L) }\end{array}$ & $\begin{array}{c}\text { Seca } \\
\text { (mg/L) }\end{array}$ \\
\hline 1 & 180 & 560 \\
\hline 2 & 120 & 440 \\
\hline 3 & 80 & 420 \\
\hline
\end{tabular}

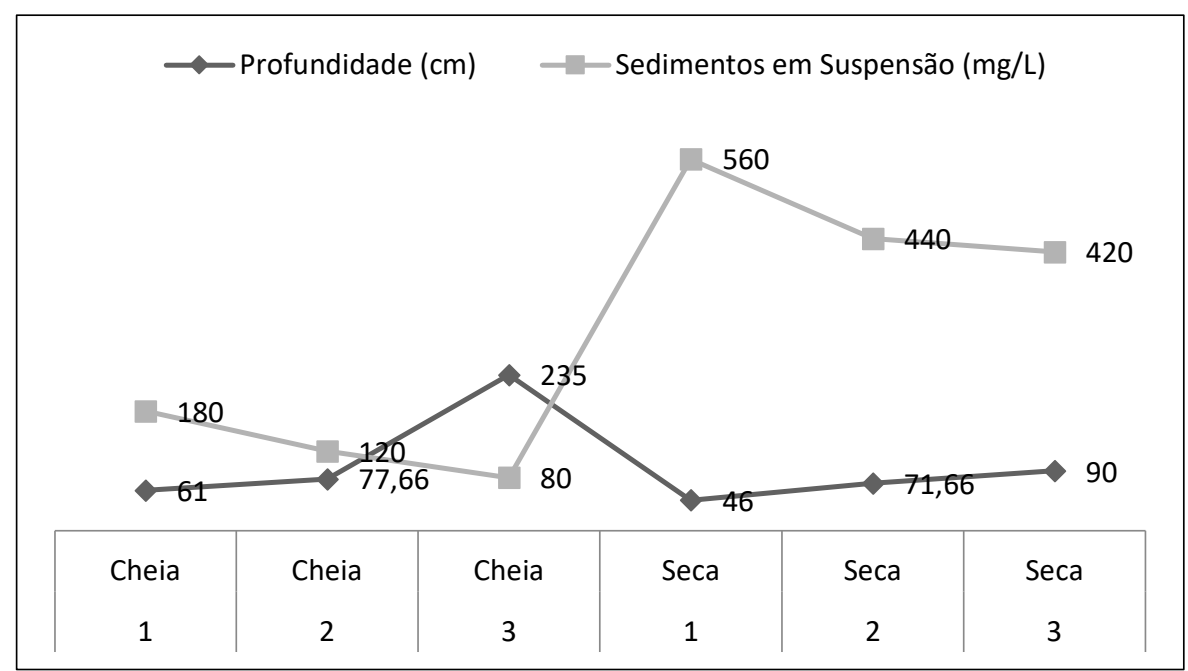

Figura 3. Valores de sedimentos em suspensão de acordo com a profundidade nas três seções de coleta para os períodos de cheia e seca do córrego Jacobina, Cáceres-MT.

\section{DISCUSSÃO}

A vazão de um canal considera a área da seção amostrada e a velocidade do fluxo das águas, assim, quanto maior a relação área $x$ velocidade, maior será a vazão. Esta variável pode, portanto, influenciar diretamente no transporte de sedimentos.

Os valores de vazão registrados neste estudo estão relacionados com a quantidade de sedimentos em suspensão, pois observou-se que nas seções de menor vazão foram registradas as maiores quantidades de sedimentos suspensos. Esta mesma tendência também pôde ser observada no estudo realizado por Souza et al. (2013) sobre a sedimentação no rio Paraguai e no baixo curso dos tributários Sepotuba, Cabaçal e Jauru no Mato Grosso.

Outro fator que está relacionado com a vazão é o período. Os dados deste estudo demonstram que a vazão diminui no período de águas baixas (seca) e embora com valores bem mais expressivos, estudos realizados por Souza et al. (2013) sobre a sedimentação no rio Paraguai e no baixo curso dos tributários Sepotuba, Cabaçal e Jauru no Mato Grosso.

De acordo com os dados observa-se uma tendência de diminuição da altura do barranco e da largura do canal comparando os períodos de cheia e seca. Apenas a primeira seção não demonstrou essa tendência aumentando a altura do barranco do período de cheia para o período de seca.

A diminuição observada da altura do barranco pode estar associada à dessedentação de animais, pois na seca, com o volume de águas mais baixo, é preciso descer mais para atingir a superfície da água e assim ocorre o deslizamento da terra do barranco, e à construção de tablado para acesso à água ou para 
pesca conforme foi observado na seção dois. Destaca-se que essas atividades promovem a entrada de sedimentos no canal que serão transportados e/ou depositados pelo movimento das águas.

Cunha (2008), afirma que capacidade da erosão do leito do rio, assim como o transporte e deposição de carga, dependem da velocidade. Neste sentido, todas as seções, com exceção da seção 2, apresentou velocidade das águas bastante baixa (Tabela 1), o que pode ter sido fator determinante para o depósito de sedimento grosseiro no fundo conforme observado na Tabela 2.

Baixos valores de velocidade do fluxo e de vazão também foram apresentados nos estudos de Faria (2014) ao estudar o transporte de sedimentos em canais fluviais de primeira ordem, registrando velocidade de $0,2 \mathrm{~m} / \mathrm{s}$ e vazão média de $4,15 \mathrm{~m}^{3} / \mathrm{s}$, bem como Silva et al. (2007) no rio Paraguai, que apresentaram dados de redução dos valores de vazão na estação seca em comparação à estação chuvosa.

A granulometria de sedimento de fundo indicou que em todas as seções de coleta, houve predomínio de areia, sendo que na cheia, a predominância foi de areia grossa na primeira seção, areia média na segunda seção e areia fina na terceira seção. Já no período de seca a primeira seção apresentou predominância de areia fina, a segunda seção de areia grossa e a terceira seção ainda teve predominância de areia fina conforme Tabela 2.

O predomínio de areia como sedimento de fundo mais frequente em todas as seções relaciona-se com as rochas areníticas presentes na bacia, oriundas das rochas sedimentares da formação Raizama, que se depositam sobre o leito do canal ao longo do tempo pelo intemperismo, uma vez que de acordo com Barros et al. (1982), esta formação apresenta em sua base frequentes intercalações de camadas de arenitos grosseiros e conglomerados com matriz arenosa fina, média e grossa.

Em todas as seções de coleta e em ambos os períodos analisados, a argila foi o sedimento de fundo encontrado em menor porcentagem (Tabela 2). Silva et al. em 2013, em estudo realizado no rio Paraguai, entre a baía do Quati e a Passagem Velha, também encontrou pequeno percentual de argila no sedimento de fundo, afirmando que argila torna o solo mais resistente a erosão devido a sua consistência. Desta forma, os menores valores registrados para este tipo de sedimento no córrego Jacobina indicam que as seções monitoradas estão mais propensas a sofrer processos erosivos.

Os dados demonstraram que no período de cheia, embora a areia tenha predominado, o tamanho do grão diminui de montante para jusante. Isto é um indicativo de que as partículas grosseiras entram no canal pelos pontos acima e ali permanecem. Um fator que pode estar associado a essa entrada de material nas seções à montante é a atividade de criação de animais, pois as margens do córrego servem de canal para a descida do animal para dessedentar, o que não ocorre na seção mais baixa que é a foz e localiza-se nos limites da Fazenda Ressaca com o rio.

A maior concentração de silte observada na seção 3 na cheia (Tabela 2) pode ser explicada pelas características do canal, já que nesta seção forma-se uma espécie de baía de águas lentas e de acordo com Suguio et al. (1990), os sedimentos mais finos têm a tendência a permanecer na massa de água, enquanto a turbulência conseguir mantê-los assim, caso contrário, a tendência é que eles sejam depositados. 
A presença de sedimentos grosseiros na bacia pode ser explicada pelas condições geológicas da bacia, pois em todo o entorno e em alguns pontos dentro do canal fluvial possuem afloramentos rochosos que pela ação do intemperismo vão sendo agregados no fundo do canal e, portanto, confundidos com sedimentos. Além disso, o material grosseiro presente nos solos do entorno do córrego pode ser levado por escoamento superficial até o canal. O predomínio da fração areia em sedimentos de fundo também foi registrado nos estudos de Leandro et al. (2012) e Bühler et al. (2012), ambos desenvolvidos no rio Paraguai.

Em trabalho realizado por Brito et al. no ano de 2009 no rio Urumajó, foi constatada a relação direta entre a preservação da mata ciliar e o tipo e tamanho de sedimento encontrado no rio. Desta forma, é possível relacionar a supressão da mata ciliar observada na bacia para investimento em pastagens e diversas culturas como soja e milho com a presença de material grosseiro.

Em relação à concentração de sedimentos em suspensão registrados neste estudo, Stegeen et al. (2000) também encontrou maior concentração de sedimentos em suspensão no período de seca em estudos em uma bacia hidrográfica na Bélgica e o resultado esteve associado às condições do solo, às chuvas e ao assoreamento, condições similares à bacia do córrego Jacobina.

Valores semelhantes aos registrados neste estudo, foram registrados por Bühler et al. (2012), ao estudar um trecho urbano do rio Paraguai em Cáceres-MT, encontrando uma variação de 57 a $221 \mathrm{mg} / \mathrm{L}$ de sedimentos em seis pontos monitorados; e por Cima et. al. (2014) no corredor fluvial do rio Paraguai, variando de 300 a $440 \mathrm{mg} / \mathrm{L}$.

\section{CONCLUSÕES}

A composição sedimentar do córrego Jacobina indica que há predomínio de material grosseiro no fundo do canal em todas as seções. A carga suspensa sofre oscilações em função dos períodos analisados e de acordo com o volume de águas. O baixo teor de argila indica suscetibilidade à erosão.

O material grosseiro encontrado no fundo no canal indica que o córrego Jacobina, recebe sedimentos provenientes de rochas sedimentares areníticas pertencentes à formação Raizama presente em toda a bacia hidrográfica.

As variáveis hidrodinâmicas, especialmente a profundidade e a largura do canal estão associadas ao volume das águas que por sua vez está relacionado ao período de chuvas e de estiagem. No entanto, outros fatores podem estar causando influência nessas variáveis à montante das seções amostradas.

A partir deste estudo foi possível relacionar as atividades desenvolvidas no entorno do córrego Jacobina que se concentram em agricultura e pecuária de corte, bem como as características naturais do ambiente como a geologia, com a composição sedimentar da bacia. No entanto, estudos estatísticos são necessários a fim de se obter um diagnóstico completo que correlacione os elementos ambientais.

\section{REFERÊNCIAS}

BARROS, A. M.; SILVA, R. H.; CARDOSO, O. R. F. A.; FREIRE, F. A.; SOUZA JUNIOR, J. J.; RIVETTI, M.; LUZ, D. S.; PALMEIRA, R. C. B.; TASSINARI, C. C. G.. Geologia. In: RADAMBRASIL. Folha
SD.21: Cuiabá: Geologia, Geomorfologia, Pedologia, Vegetação e Uso potencial da terra. Rio de Janeiro, 1982. 
BRITO, R. N. R.; A.S.P, N.E; BEASLEY, C.R; SANTOS, H.S.S dos. Características Sedimentares Fluviais Associadas ao Grau de Preservação da Mata Ciliar - Rio Urumajó, Nordeste Paraense. Revista Acta Amazônica, v.39, n.1, p.173-180, 2009.

BUHLER, B. F.; SOUZA, C. A.. Aspectos sedimentares do Rio Paraguai no perímetro urbano de Cáceres - MT. Revista Geociências, São Paulo, v.31, n.3, p.339-349, 2012.

CARVALHO, N. O.; FILIZOLA JÚNIOR, N. P.; SANTOS, P. M. C.; LIMA, J. E. F. W.. Guia de práticas sedimentométricas. Brasília: ANEEL, 2000.

CHRISTOFOLETTI, A.. Geomorfologia. São Paulo: USP, 1977.

CIMA, E. F.; ANDRADE, L. N. P. S.; SOUZA, C. A.; SANTOS, M.; LENADRO, G. R. S. Frequência granulométrica e deposição de sedimentos em ambientes do corredor fluvial do rio Paraguai, pantanal superior, Mato Grosso. Cadernos de Geociências, v.11, n.1-2, p.1-6, 2014.

CUNHA, S. B.. Geomorfologia Fluvial. In: GUERRA. A. J. T.; CUNHA, S. B.. Geomorfologia: uma atualização de bases e conceitos. Rio de Janeiro: Bertrand do Brasil, 2008.

EMBRAPA. Empresa Brasileira de Pesquisa Agropecuária. Manual de métodos de análises de solo. 2 ed. Rio de Janeiro: Embrapa, 1997.

FARIA, A. P.. Transporte de sedimentos em canais fluviais de primeira ordem: respostas geomorfológicas. Revista Brasileira de Geomorfologia, São Paulo, v.15, n.2, p.191202, 2014. DOI: http://dx.doi.org/10.20502/rbg.v15i2.410

FRINGS, R. M.; DORING, R.; BECKHAUSEN, C.; SHUTTRUMPF, H.; VOLLMER, S.. Fluvial sediment budget of a modern, restrained river: The lower reach of the Rhine in Germany. Revista Catena, Cremlingen, n.122, p.91-102, 2014. DOI: https://doi.org/10.1016/j.catena.2014.06.007

LEANDRO, G. R. S.; SOUZA, C. A.. Pantanal de Cáceres: composição granulométrica dos sedimentos de fundo no rio Paraguai entre a foz do rio Cabaçal e a cidade de Cáceres, Mato Grosso, Brasil. Revista Ambi-Agua, Taubaté, v.7, n.2, p.263-276, 2012. DOI: http://dx.doi.org/10.4136/ambiagua. 876
LUIZ, A. M. E.; PINTO, M. G. C.; SCHEFFER, E. W. O..

Parâmetros de cor e turbidez como indicadores de impactos resultantes do uso do solo, na bacia hidrográfica do rio Taquaral, São Mateus do sul-PR. Revista RA'E GA, Curitiba, n.24, p.290-310, 2012. DOI:

http://dx.doi.org/10.5380/raega.v24i0.26264

MARTINS, D. P.; STEVAUX, J. C.. Formas de leito e transporte de carga de fundo do alto rio Paraná. Revista Brasileira de Geomorfologia, São Paulo, v.6, n.2, p.43-50, 2005. DOI: http://dx.doi.org/10.20502/rbg.v6i2.50

SILVA, F. C.; FREITAS, I. J.; CRUZ, J. S. B.; OLIVEIRA, M. A. P.; SOUZA, C. A.; ANDRADE, L. N. P. S.; BAMPI, A.. Rio Paraguai no pantanal de Cáceres - Mato Grosso: feições morfológicas e deposição de sedimento. Revista Mato-Grossense de Geografia, Cuiabá, n.16, p.39-60, 2013.

SILVA, A.; SOUZA, C. A. ZANI, H.; FREITAS, D. R.. Avaliação da margem direita do rio Paraguai a jusante da praia do Juliãomunicípio de Cáceres (MT). Revista Geográfica Acadêmica, v.1, n.1, p.5-19, 2007. DOI: http://dx.doi.org/10.18227/1678-7226rga.v1i1.2963

SOUZA, C. A.; SOUSA, J. B.; LEANDRO, G. R. S.; SILVA, L. A.; SANTANA, M.; SANTOS, M.. Sedimentação no rio Paraguai e no baixo curso dos tributários Sepotuba, Cabaçal e Jauru, Mato Grosso, Brasil. In: ENCONTRO DE GEÓGRAFOS DA AMÉRICA LATINA, 14. Anais. Egal: 2013.

SUGUIO, K.. Introdução à sedimentologia. São Paulo: Edgar Blucher, 1973.

SUGUIO, K.; BIGARELLA, J. J.. Ambientes Fluviais. Florianópolis: UFSC, 1990.

TANANAEV, N. I.; DEBOLSKIY, M. V.. Turbidity observations in sediment flux studies: Examples from Russian rivers in cold environments. Geomorphology, Amsterdam, v.218, p.63-71, 2013. DOI: https://doi.org/10.1016/j.geomorph.2013.09.031

STEGEEN, A.; GOVERS, G.; NACHTERGAELE, J.; TAKKEN, I.; BEUSELINK, L.; POESEN, J.. Sediment export by water from an agricultural catchment in the Loam Belt of central Belgium. Geomorphology, 2000. DOI: https://doi.org/10.1016/S0169-555X(99)00108-7

A CBPC - Companhia Brasileira de Produção Científica (CNPJ: 11.221.422/0001-03) detém os direitos materiais desta publicação. Os direitos referem-se à publicação do trabalho em qualquer parte do mundo, incluindo os direitos às renovações, expansões e disseminações da contribuição, bem como outros direitos subsidiários. Todos os trabalhos publicados eletronicamente poderão posteriormente ser publicados em coletâneas impressas sob coordenação da Sustenere Publishing, da Companhia Brasileira de Produção Científica e seus parceiros autorizados. Os (as) autores (as) preservam os direitos autorais, mas não têm permissão para a publicação da contribuição em outro meio, impresso ou digital, em português ou em tradução. 